Article

\title{
Antifungal and Antibacterial Effect of Propolis: A Comparative Hit for Food-Borne Pseudomonas, Enterobacteriaceae and Fungi
}

\author{
Leonardo Petruzzi, Maria Rosaria Corbo ${ }^{\mathbb{D}}$, Daniela Campaniello, Barbara Speranza, \\ Milena Sinigaglia * and Antonio Bevilacqua * D \\ Department of the Science of Agriculture, Food and Environment, University of Foggia, 71122 Foggia, Italy; \\ leonardo.petruzzi@unifg.it (L.P.); mariarosaria.corbo@unifg.it (M.R.C.); daniela.campaniello@unifg.it (D.C.); \\ barbara.speranza@unifg.it (B.S.) \\ * Correspondence: milena.sinigaglia@unifg.it (M.S.); antonio.bevilacqua@unifg.it (A.B.)
}

Received: 25 March 2020; Accepted: 20 April 2020; Published: 2 May 2020

check for updates

\begin{abstract}
Propolis is a natural brownish resinous substance collected by honeybees (Apis mellifera), with a documented bioactivity against many microorganisms. In this study, the activity of propolis was investigated using some strains of Pseudomonas spp., Enterobacteriaceae, Lactobacillus plantarum, yeasts (Saccharomyces cerevisiae and Debaryomyces hansenii) and Fusarium oxysporum. Two approaches were used (a modified microdilution protocol and viable count), and the microorganisms were inoculated at two levels (low or high inoculum). The antimicrobial effect of propolis relies upon several factors, like the kind of microorganisms (for example S. cerevisiae was more resistant than $D$. hansenii, while Lactobacillus plantarum was never affected), the cell concentration (at high inoculum higher amounts of propolis were required for an antimicrobial action), and the mode of action (a delay of growth rather than a complete inhibition). The results of this paper point out, for the first time, the antimicrobial activity of propolis against some spoilers, with a focus on the possible effect; thus, they could be the background to designing an effective tool to prolong the shelf life of foods.
\end{abstract}

Keywords: growth index; viable count; growth kinetic; biostatic effect

\section{Introduction}

Products of natural origin have been used in traditional medicine for throughout history and represent a potential source of new drugs. Propolis is an example of such a remedy with an interesting antimicrobial activity known since the time of ancient Egyptians and Greeks [1].

The antimicrobial activity of propolis has been extensively reviewed by different authors; it is well known that it is able to inhibit and/or control the growth of a wide range of microorganisms, either Gram positive (Listeria monocytogenes, Staphylococcus spp., Streptococcus spp., Bacillus spp.) or Gram negative bacteria (Escherichia coli, Klebsiella pneumoniae, Enterobacter cloacae, Pseudomonas aeruginosa), as well as yeasts and molds (Candida spp., Aspergillus spp., Penicillium digitatum, Saccharomyces cerevisiae, Cladosporium spp., Trychophyton spp., Alternaria alternata and Fusarium oxysporum) [2-8]. Propolis is composed of more than 300 different components, like polyphenol (flavonoids, phenolic acids and esters), phenolic aldehydes and ketones. The percentage of these substances is as follows: resins and vegetable balsam 50\%, Bee wax 30\%, pollen 5\%, essential and aromatic oils 10\%, and some other substances which include organic compounds as well [9]. The composition is affected by the extraction methods; it is generally produced through an ethanol-extraction, although some steps (like maceration) are variable [10].

The bioactivity relies upon different factors, like (a) origin: European propolis possess a different range of bioactivity than Brazilian or Korean ones, due probably to the different qualitative composition 
in phenols; (b) the strain, as the effect is strongly strain-dependent; moreover, the inhibition of Gram negative bacteria is controversial; (c) the protocol used to assess in vitro bioactivity, due to the low solubility of some extracts; (d) the use in laboratory media or in foods, as it has been reported that the essential oils and plant extracts can interact with food components; (e) the use of propolis as food ingredients or loaded in a coating [11-17].

Generally, the antimicrobial activity of propolis has been assessed through the viable count and the results reported as the decrease in cell count compared to the control; however, this approach has a drawback, in that is it is not possible to pinpoint an effect different from the biocidal one.

The effects of plant extracts could be reversible and act on the biomass rather than on the viable population; this effect was reported for different extracts and phenol-related compounds at low or sub-inhibitory concentrations $[18,19]$. Thus, we propose two protocols to study the bioactivity of propolis in lab media: the classical one based on the viable count at high concentrations and the Growth index approach for relatively low amounts (200-1000 ppm) to build a comparative hit on the resistance/susceptibility of some microorganisms to propolis as a prodromal step for application in food processing.

\section{Materials and Methods}

\subsection{Microorganisms and Media}

Strains and their source are listed in Table 1. The following media were used: (i) Yeast Peptone Glucose broth and Agar (YPG) (yeast extract, $10 \mathrm{~g} / \mathrm{L}$; bacteriological peptone, $10 \mathrm{~g} / \mathrm{L}$; glucose, $20 \mathrm{~g} / \mathrm{L}$; agar, $12 \mathrm{~g} / \mathrm{L}$ ) for yeasts; (ii) Potato Dextrose Agar (PDA) for Fusarium oxysporum; (iii) MRS broth and Agar (Oxoid) for Lactobacillus plantarum; (iv) Nutrient broth and Agar (Oxoid), for Pseudomonas spp. and Enterobacteriaceae. PDA, MRS broth and Agar, and Nutrient broth and Agar are commercial products (Oxoid, Basingstoke, UK).

Table 1. Microorganisms.

\begin{tabular}{cc}
\hline Target & Source \\
\hline Pseudomonas putida (PSE8) & Wild strain isolated from mozzarella cheese \\
Pseudomonas fluorescens (PSE5) & Wild strain isolated from mozzarella cheese \\
Hafnia alvei (COL8) & Wild strain isolated from mozzarella cheese \\
Enterobacter spp. (COL9) & Wild strain isolated from mozzarella cheese \\
Lactobacillus plantarum (L12) & Wild strain isolated from sourdough \\
Lactobacillus plantarum DSM1055 & Collection strain \\
Debaryomyces hansenii DSM3428 & Collection strain \\
Saccharomyces cerevisiae EC1118 ** & Commercial wine strain \\
Fusarium oxysporum DSM2018 & Collection strain \\
\hline
\end{tabular}

* Deutsche Sammlung von Mikroorganismem und Zellkulturen's collection- Braunschweig, Germany; ** Lallemande (Canada).

\subsection{Propolis}

Propolis from an Italian pharmaceutical factory was used throughout this study; the concentration of phenolic compounds was about 30\%. Stock solutions (20,000-300,000 ppm; these concentrations, as well as those reported in the following sections, were for the amounts of propolis in the solution) were prepared in a hydro-alcoholic solution (1:1); ethanol (96\%) was used as alcohol. One-hundred or two-hundred $\mu \mathrm{L}$ of stock solutions were added to the samples in order to achieve the desired concentrations (from 200 to 3000 ppm).

\subsection{Growth Index of Bacteria and Yeasts}

Aliquots of optimal media (20 mL; YPG broth for yeasts, Nutrient broth for Pseudomonas spp. and Enterobacteriaceae, MRS broth for lactic acid bacteria) were supplemented with $200 \mu \mathrm{L}$ of stock 
solutions to attain a final concentration of the extract ranging from 200 to $1000 \mathrm{ppm}$ and inoculated to $3 \log$ or to $5 \log \mathrm{cfu} / \mathrm{mL}$. Two kinds of controls were prepared: (i) media + hydroalcoholic solution (growth of the target strains); (ii) broths supplement with either chloramphenicol (for the experiments on bacteria, $200 \mathrm{mg} / \mathrm{L}$ ) (Sigma-Aldrich, Milan) or cycloheximide (experiments with yeasts, $200 \mathrm{mg} / \mathrm{L}$ ) (Sigma-Aldrich) (samples with no growth). Both controls were inoculated to 3 or 5 log cfu/mL.

Samples were stored at $25^{\circ} \mathrm{C}$ (yeasts and Pseudomonas spp.), $30^{\circ} \mathrm{C}$ (lactic acid bacteria), and $37^{\circ} \mathrm{C}$ (enterobacteria). Microbial growth was evaluated after 24 and $48 \mathrm{~h}$ as absorbance at $600 \mathrm{~nm}$ with a spectrophotometer UV-VIS DU 640 Beckman (Fullerton, California, USA).

The analyses were performed in duplicate and data were modelled as Growth Index (GI) [20]:

$$
G I=\left(\frac{A b s_{s}}{A b s_{c}}\right) * 100
$$

where $A b s_{s}$ is the absorbance of the samples containing the different amounts of propolis and $A b s_{c}$ the absorbance of inoculated media containing only hydroalcoholic solution. The analyses were performed in duplicate over two independent batches.

GI was read as follows [18]: GI $<25 \%$, significant inhibition; $25 \%<G I<75 \%$, partial inhibition; $G I>75 \%$, growth similar to positive control.

For each time of sampling (after 24 or $48 \mathrm{~h}$ ), GI was modelled as a function of propolis concentration through the equation of Weibull, modified by Mafart et al. [21] and cast in the following form:

$$
G I=G I_{0}-\left(\frac{c}{\delta}\right)^{p}
$$

where: $G I$ is the Growth index as a function of propolis concentration (dependent variable, $\%$ ); $G I_{0}$, the GI of the positive control (broth+hydroalcoholic solution); $c$, the amount of propolis (independent variable, ppm); $\delta$, the amount of propolis (ppm) to achieve a reduction of GI by $1 \% ; p$, the shape parameter (dimensionless), which gives some details on the shape of the kinetic: $p<1$, upward curve; $p=1$, linear kinetic; $p>1$, downward curve.

The parameter $\delta$ was the input for the evaluation of $\Delta 25$, that is the amount of propolis required to reduce GI by $25 \%(\delta \times 25)$. Statistic was performed through the software Statistica for Windows, ver. 7.0 (Statsoft, Tulsa Oklha).

\subsection{Viable Count of Bacteria and Yeasts}

Aliquots of $10 \mathrm{~mL}$ of optimal media (YPG broth for yeasts, Nutrient broth for Pseudomonas spp and Enterobacteriaceae) were individually inoculated to $5 \log \mathrm{cfu} / \mathrm{mL}$ with the test strains and added with $100 \mu \mathrm{L}$ of propolis stock solutions to attain a final concentration ranging between 1000 and $3000 \mathrm{ppm}$. Two kinds of controls were prepared: (i) media + hydroalcoholic solution $(100 \mu \mathrm{L}$ in $10 \mathrm{~mL})$; (ii) broths supplement with wither chloramphenicol (for the experiments on bacteria, $200 \mathrm{mg} / \mathrm{L}$ ) or cycloheximide (experiments with yeasts, $200 \mathrm{mg} / \mathrm{L}$ ). Both controls were inoculated to $5 \log \mathrm{cfu} / \mathrm{mL}$.

The samples were stored under static conditions and the growth of the targets was assessed after 24 and $48 \mathrm{~h}$ by plate count. The media were the following ones: (i) MRS agar, incubated at $30^{\circ} \mathrm{C}$ for $48-72 \mathrm{~h}$ under anaerobic conditions for lactic acid bacteria; (ii) YPG agar, incubated at $25^{\circ} \mathrm{C}$ for $48 \mathrm{~h}$ for yeasts; (iii) Nutrient agar incubated at $25^{\circ} \mathrm{C}$ for $48 \mathrm{~h}$ for Pseudomonas spp. or at $37^{\circ} \mathrm{C}$ for $18-24 \mathrm{~h}$ for Enterobacteriaceae. The analyses were performed in duplicate over two different batches.

Data were modelled as increase in viable count compared to the inoculum; this value was modelled through MANOVA (multifactorial analysis of variance). The concentration of propolis, the kind of microorganisms and time were used as categorical predictors. The critical $p$ was set to 0.05 . 


\subsection{Antifungal Activity}

The antifungal activity of propolis was tested towards F. oxysporum (DSM 2018). The mould was grown on Potato Dextrose Agar (PDA) incubated at $25^{\circ} \mathrm{C}$ for 5 days. A conidia suspension was prepared by washing the mould grown on PDA plates with a Tween 80 solution $(0.05 \% v / v)$ (C. Erba); conidia suspension $\left(10^{7}\right.$ conidia/mL) was filtered to avoid the presence of mycelium [22].

After the sterilization, aliquots of stock solutions were added to PDA $\left(55^{\circ} \mathrm{C}\right)$ in order to achieve the desired amount of propolis (1000-1500-2000-2500-3000 ppm) (1 mL of stock solution in $100 \mathrm{~mL}$ of medium); PDA + hydroalcoholic solution was used as positive control. Twenty $\mu \mathrm{L}$ of conidia suspension were inoculated in the middle of plates. Incubation was carried out in the dark at $25 \pm 2{ }^{\circ} \mathrm{C}$ and colony diameters were measured in centimeters and compared with those on controls plates at intervals of 2 days for 10-14 days in order to determine the radial growth.

The experiments were performed on three independent batches; for each batch, the analyses were made in duplicate. Fungal growth was modeled by using a logistic equation, modified by Dantigny et al. [23] and cast in the following form:

$$
D=\frac{D \max }{1+\exp [k(\tau-t)]}
$$

where $D$ is the diameter of the fungal colony over time; $D_{\max }$, the maximum diameter of fungal colony; $k$, the rate of fungal growth (cm/day); $\tau$, the time to attain a $\frac{1}{2}$ of $D_{\max }$ (day) and $t$ the time (day).

\section{Results and Discussion}

Propolis, a natural product of honey bee, has been attracting the attention of researchers due to its various biological activities and therapeutic properties. Flavonoids, aromatic acids, diterpenic acids, and phenolic compounds appear as the principal components that are responsible for the biological activities of propolis samples [24]. Many studies have documented the remarkable action of propolis against viruses, parasites and many types of microorganisms (yeasts, and bacteria) [25].

The first experiment of this research was the evaluation of the antimicrobial activity of different concentrations of propolis through a modified micro-dilution approach; the microorganisms were inoculated at low and high levels and the Growth Index (GI) was evaluated, as reported by Bevilacqua et al. [20]. The use of low and high inocula was chosen for modelling purposes; low inocula (GI approach) are useful to build growth kinetics or dose/response curves when the main purpose is to study the amount of antimicrobial at low doses and the expected outcome is a delay of growth rather than a complete inhibition. On the other hand, at higher doses it is suggested to used high inocula, because a possible outcome could be a death kinetic.

The microorganisms were chosen for different reasons: enterobacteria are generally the target microorganisms for some foods (for example dairy products), according to EU regulations, while Pseudomonas spp. are emerging spoilers, able to start the spoilage of a wide variety of foods [26]. $L b$. plantarum was used as representative of lactic acid bacteria, because it is widespread in a variety of foods and can be both a technological microorganism (for example starter culture for mozzarella cheese) or a spoiler. Finally, yeasts and F. oxysporum were chosen because they can be found in meat (D. hansenii), as well as in vegetables or in beverages (S. cerevisiae and F. oxysporum) $[27,28]$.

$G I$ is a tool to point out a significant inhibition due to an antimicrobial compound, if compared to the positive control; it is time-dependent, as it generally changes throughout time if the effect of the antimicrobial compound is reversible.

Therefore, in this paper a static approach was used and for each time of sampling GI was modelled as a function of propolis concentration; the use of a static approach (description of a situation for a defined time) was proposed elsewhere as a tool to exclude time-dependence [29]. Generally, GI at $48 \mathrm{~h}$ were used as input data for modelling except for S. cerevisiae (GI at $24 \mathrm{~h}$ ). Figure 1 shows GI profile at $48 \mathrm{~h}$ for pseudomonads and enterobacteria for low inoculum; all strains experienced an upward linear 
kinetic with a decrease in GI when the propolis amount increased (GI was 32\%-48\% at $1000 \mathrm{ppm}$ ), thus suggesting that propolis did not cause a complete inhibition but a significant delay of growth.

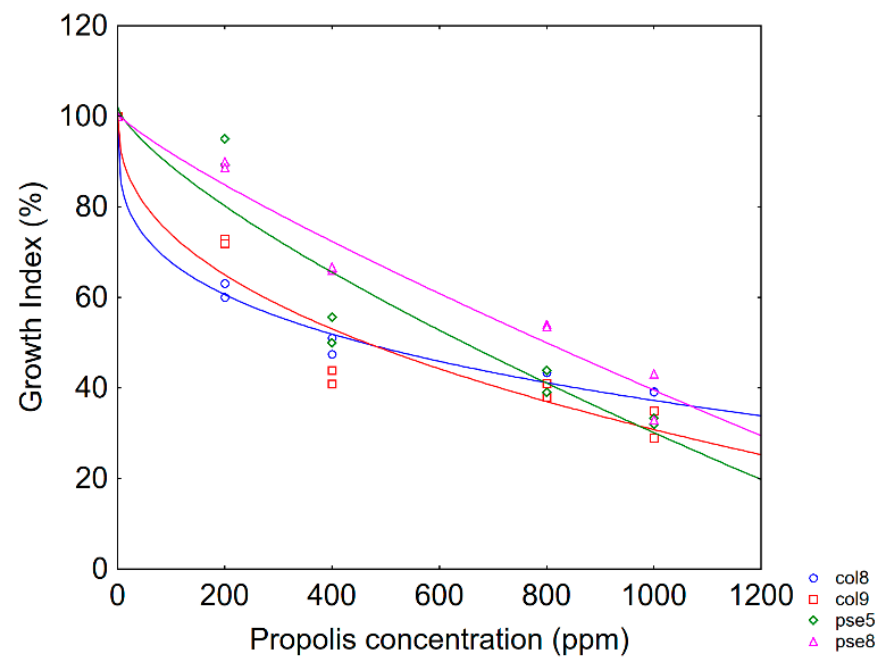

Figure 1. Dose response profile (Growth Index vs. propolis concentration) for pseudomonads and enterobacteria after $48 \mathrm{~h}$. The lines represent the best fitting of data through Weibull model. col8, $H$. alvei; col9, Enterobacter spp.; pse5, Ps. fluorescens; pse8, Ps. putida. Micro-dilution approach for low-level inoculum $(3 \log \mathrm{cfu} / \mathrm{mL})$.

Figure 2 shows the GI profiles for yeasts (low inoculum). S. cerevisiae was more resistant than D. hansenii as it experienced a downward curve after $24 \mathrm{~h}$; this curve was characterized by a shoulder length of $645 \mathrm{ppm}$, that is the growth was not affected up to this critical break point. After $48 \mathrm{~h}$, GI of S. cerevisiae was not affected by propolis, while $D$. hansenii showed an upward curve with a significant negative correlation GI/propolis concentration.

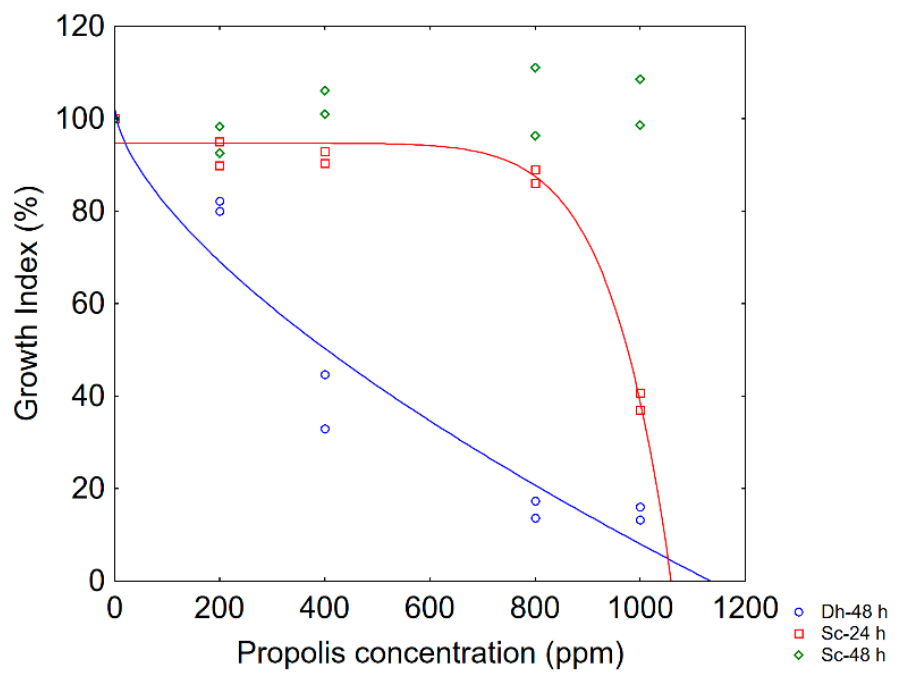

Figure 2. Dose response profile (Growth Index vs. propolis concentration) for yeasts after 24 or $48 \mathrm{~h}$. The lines represent the best fitting of data through the Weibull model. S.c., S. cerevisiae; D.h., D. hansenii. Micro-dilution approach for low-level inoculum (3 log cfu/mL).

The fitting parameters of the Weibull equation and $\Delta 25$ are shown in Table 2. $\Delta 25$ was strongly species-dependent and was $<10 \mathrm{ppm}$ for both enterobacteria; pseudomonads were more resistant, with $\Delta 25$ ranging from $77 \mathrm{ppm}$ (Ps. fluorescens) to $186 \mathrm{ppm}$ (Ps. putida). Finally, $\Delta 25$ was $23.50 \mathrm{ppm}$ for D. hansenii. Modelling was not performed for Lactobacillus spp., because the strains always experienced a GI of $90 \%-100 \%$ (data not shown). 
Table 2. Parameters of Weibull equation: $\delta$, amount of propolis ( $\mathrm{ppm}$ ) to achieve a reduction in Growth Index of $1 \%$; $p$, shape parameter ( $p<1$, upward curve; $p>1$, downward curve); $\Delta 25$, amount of propolis (ppm) to achieve a reduction of Growth Index of $25 \%$; $\mathrm{R}^{2}$, determination coefficient. Micro-dilution approach for low-level inoculum $(3 \log \mathrm{cfu} / \mathrm{mL})$.

\begin{tabular}{cccccc}
\hline Microorganism & Time & $\boldsymbol{\delta}$ & $\boldsymbol{p}$ & $\mathbf{\Delta 2 5}$ & $\mathbf{R}^{\mathbf{2}}$ \\
\hline D. hansenii & $48 \mathrm{~h}$ & $0.94 \pm 0.11$ & $0.65 \pm 0.09$ & 23.50 & 0.935 \\
S. cerevisiae & $24 \mathrm{~h}$ & $645.73 \pm 69.04$ & $9.20 \pm 2.10$ & $/ \dagger$ & 0.977 \\
& $48 \mathrm{~h}$ & - & - & - & - \\
Ps. fluorescens & $48 \mathrm{~h}$ & $3.07 \pm 0.22$ & $0.74 \pm 0.05$ & 76.75 & 0.909 \\
Ps. putida & $48 \mathrm{~h}$ & $7.44 \pm 1.25$ & $0.84 \pm 0.01$ & 186.00 & 0.962 \\
H. alvei & $48 \mathrm{~h}$ & $0.01 \pm 0.01$ & $0.29 \pm 0.01$ & $<10$ & 0.990 \\
Enterobacter sp. & $48 \mathrm{~h}$ & $0.04 \pm 0.01$ & $0.42 \pm 0.03$ & $<10$ & 0.941 \\
\hline
\end{tabular}

† Not evaluated.

When the microorganisms were inoculated at high levels, they never experienced inhibition and the GI at 1000 ppm was $76 \%-89 \%$ (data not shown). The GI in the samples with antibiotic was always $0 \%$, both at low and high inocula (data not shown).

The effect of propolis for the high inoculum level was studied by increasing the amount of the extract; however, a different approach was used (plate count), because a high amount of propolis caused a strong browning of some media (mainly Nutrient broth). The data of viable count were standardized as increase in viable count after 24 or $48 \mathrm{~h}(\Delta \mathrm{C})$ and analyzed through a multifactorial ANOVA (MANOVA). Lactobacillus spp. always experienced a viable count of $9 \log \mathrm{cfu} / \mathrm{mL}$ and did not show any kind of inhibition; therefore, their data were not used for statistic (data not shown).

$\Delta \mathrm{C}$ was generally positive, thus suggesting that populations increased throughout time. However, MANOVA was affected by both propolis concentration and time, as well as by their interactive terms (propolis concentration*time, time*microorganism, propolis concentration*time*microorganism) $(p<0.05)$. The results of MANOVA are shown in the figures for the decomposition of the statistical hypothesis (Figure $3 \mathrm{~A}-\mathrm{C}$ ).


Figure 3. Decomposition of the statistical hypothesis on the increase of viable count of yeast and bacteria. Bars denote $95 \%$ confidence intervals. (A), effect of propolis concentration; (B), effect of time; (C), effect of kind of microorganism. a, D. hansenii; b, S. cerevisiae; c, H. alvei (col8); d, Enterobacter sp. (col9); e, Ps. fluorescens; f, Ps. putida. 
As expected, $\Delta C$ was a function of propolis amount (Figure $3 \mathrm{~A}$ ) with a negative correlation; in fact, $\Delta C$ decreased when propolis concentration increased, thus suggesting that higher amounts of propolis could be more effective in controlling the growth of some strains. Figure 3B shows the effect of time, with a "false" negative correlation time/bioactivity of propolis, as suggested by the increase in the viable count over time; this effect was due to the fact that propolis generally caused a delay of growth and probably determined an increase in the lag phase or a reduction in growth rate in the bacterial or yeast-kinetic.

Finally, Figure $3 \mathrm{C}$ shows the effect of the kind of microorganism; this figure could be used to point out a kind of resistance hit: $D$. hansenii was less resistant than $S$. cerevisiae. Among bacteria, Pseudomonas spp. were more resistant than enterobacteria; for enterobacteria, $H$. alvei was more resistant than Enterobacter sp.

Concerning the anti-yeast effect, De Castro et al. [30] suggested that $0.125 \%$ (1250 ppm) propolis could be an adequate choice as a sub-inhibitory concentration for S. cerevisiae, thus confirming the strong resistance of this species as found both for GI and viable count. The authors suggested a dual role for propolis treatment as an agent that induces apoptosis and secondary necrosis; in addition, propolis inhibited respiration in S. cerevisiae. Regarding D. hansenii, Sidra [31] reported 0.4 and $0.8 \mathrm{mg} / \mathrm{mL}$ (ranging from 400 to $800 \mathrm{ppm}$ ) as the Minimum Inhibitory Concentrations (MIC) in orange and apple juice, respectively.

For the antibacterial effect of propolis, it is generally assumed that that Gram positive bacteria are sensitive to low propolis concentration and Gram-negative bacteria could be only inhibited with higher propolis dose [25]; therefore, few data are available on Gram negative and some results could be found on pathogens (Yersinia enterocolitica, Ps. aeruginosa, Escherichia coli, Salmonella sp., etc.) [32-35]. However, to the best of our knowledge, few data are available on the spoilers, such as Pseudomonas spp., which are a challenge for food producers.

It has been suggested that the resistance of Gram-negative bacteria could be due to the presence of efflux pumps preventing the intracellular entry of propolis constituents. The weak effect on Gram-negative bacteria may also be explained by the fact that propolis contains mainly plant-derived resin constituents and that resins are secreted by plants to mostly protect from Gram-positive pathogens [36].

The data of this research suggest that propolis could be used for the inhibition of Gram-negative bacteria, although pseudomonads require medium-to high levels, thus confirming the resistance of pseudomonads to extracts $[37,38]$. Some authors studied the mode of action of propolis towards Ps. aeruginosa and found that propolis impaired the growth, the production of biofilm and the capacity to release molecules, such as phenazines and eDNA with a possible role of complex phenols [39].

Although the effect of propolis on Gram negative was reported as low or moderate, the data of this research showed a strong effect on the delay of growth kinetic for enterobacteria, due probably to a higher sensitivity of the tested strains. For these microorganisms, multiple effects could be responsible for the antibacterial activity, including the inhibition of cell division, and protein synthesis [9].

Another effect found on the tested target was the dependence of the antimicrobial effect on the cell concentration, as at high inoculum, an effect of propolis was found only at high doses. This is a new evidence and further investigations are required. Finally, the resistance of $L b$. plantarum to propolis was probably the result of the high resistance of this species to phenols (complex or simple phenolic compounds) reported elsewhere by the authors [40].

The antifungal effect of propolis was tested towards F. oxysporum by assessing the radial growth on plates. Figure 4 shows some examples of fungal kinetics; they generally experienced a logistic-like shape, characterized by a three-phase kinetic (a lag phase, an exponential growth phase and a steady state); thus, they were modelled through a logistic function (the equation of Dantigny et al. [23]). 


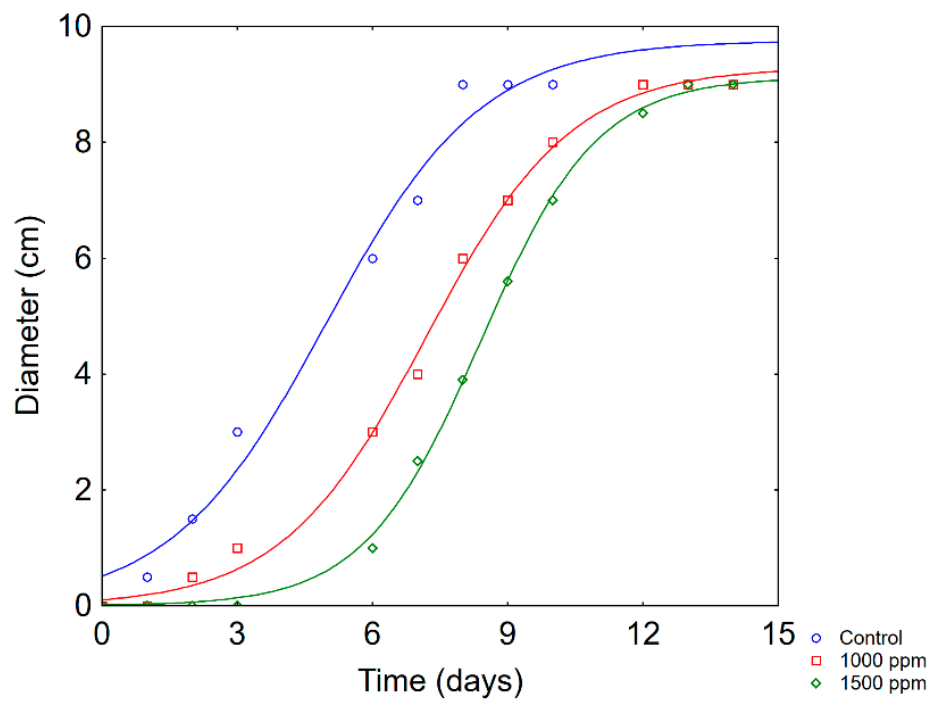

Figure 4. Growth kinetic of F. oxysporum on plates as a function of propolis concentration; the points represent the average of three determinations. Lines are the best fit through Dantigny model.

For fungi, the fitting parameters of a sigmoid have a different meaning if compared to a bacterial kinetic; Dantigny function has a main parameter, that is the time to attain a $\frac{1}{2}$ of the maximum diameter $(\tau)$, which is an estimation of both the first step (no growth) and fungal growth rate (exponential phase) (Table 3). $\tau$ was $4.98 \pm 0.44$ days in the positive control and increased to $7.20 \pm 0.11$ days on PDA + $1000 \mathrm{ppm}$ propolis and $8.40 \pm 0.06$ on PDA $+1500 \mathrm{ppm}$ propolis; a further increase of propolis did not significantly act on $\tau$.

Table 3. F. oxysporum $\tau$ (time to attain a $\frac{1}{2}$ of the maximum diameter) (day) on PDA + propolis (5-15\%). Mean values \pm standard error. $\mathrm{R}^{2}$, determination coefficient of Dantigny model. The letters indicate significant differences (one-way ANOVA and Tukey's test, $p<0.05$ ).

\begin{tabular}{ccc}
\hline Propolis Amount & $\boldsymbol{\tau}$ & $\mathbf{R}^{\mathbf{2}}$ \\
\hline 0 (control) & $4.98 \pm 0.44 \mathrm{a}$ & 0.985 \\
$1000 \mathrm{ppm}$ & $7.20 \pm 0.11 \mathrm{~b}$ & 0.997 \\
$1500 \mathrm{ppm}$ & $8.40 \pm 0.06 \mathrm{c}$ & 0.999 \\
$2000 \mathrm{ppm}$ & $8.33 \pm 0.08 \mathrm{c}$ & 0.998 \\
$2500 \mathrm{ppm}$ & $8.42 \pm 0.08 \mathrm{c}$ & 0.998 \\
$3000 \mathrm{ppm}$ & $8.29 \pm 0.09 \mathrm{c}$ & 0.997 \\
\hline
\end{tabular}

The results on the antifungal activity are generally in line with the literature. According to AL-Ani et al. [25], propolis possess a moderate antifungal activity. Ôzcan [41] reported that the concentration of $4 \%$ of propolis extract is able to inhibit $F$. oxysporum f. sp. melonis by $50 \%$. In another study [42], $5 \mathrm{mg} / \mathrm{mL}$ (5000 ppm) of ethanol extract of propolis completely inhibited the radial growth of F. oxysporum on solid media (PDA). Various compounds like phenolics and flavonoids are responsible for their antifungal activity by affecting the permeability of the cytoplasmic membrane, which leads to the total leakage of the cellular constituents such as nucleic acids, proteins and inorganic ions such as phosphate and potassium, leading to complete cell death [43].

Generally, the effects of propolis resulted in a delay of fungal or bacterial growth, as suggested by the reduction in GI as well as by the increase in $\tau$ for F. oxysporum; however, further investigations are required to elucidate some key-points related to food applications. An open question is the evaluation of MIC, NIC (Not Inhibitory Concentration) [44] and the dose/response profile. The results of this paper suggest a MIC $>3000 \mathrm{ppm}$, with an NIC ranging from $10 \mathrm{ppm}$ (reduction in GI by $25 \%$ for enterobacteria) to $645 \mathrm{ppm}$ (shoulder length of S. cerevisiae). The high MIC suggests a possible application in designing food-packaging materials or edible coatings, rather than use as ingredients in 
food formulas. In fact, the high doses required for propolis bioactivity are not compatible for a direct application, due to the possible strong impact on the organoleptic characteristic of foods.

On the other hand, the filming properties of propolis [45,46], along with the delay of some spoilers as suggested in this paper, could be the background to design an active packaging for dairy products, meat, or vegetables.

\section{Conclusions}

The antimicrobial effect of propolis relies upon several factors, and this research contributed to point out some of them. First, the effect was strongly related to the kind of microorganisms; for yeasts, $D$. hansenii was more affected than S. cerevisiae. Concerning bacteria, Lb. plantarum was never affected, while propolis controlled the growth of both Pseudomonas and Enterobacteriaceae. Another significant effect was related to cell concentration, because at high inoculum no (or very mild) effect was found; finally, propolis delayed the radial growth of F. oxysporum, as suggested by the increase in the parameter $\tau$. The results of this paper point out, for the first time, the antimicrobial activity of propolis against some food spoilers, with a focus on the possible effect (that is, the delay of growth rather than a complete inhibition). However, further investigations are required to point out an exact definition of the dose response/curve of propolis (MIC), as a prodromal step for a possible application in food industry (packaging, new edible coatings).

Author Contributions: Conceptualization, M.S., M.R.C. and A.B.; methodology, A.B.; formal analysis, L.P., D.C., B.S. and A.B.; investigation, L.P., D.C., B.S. and A.B.; resources, M.S. and M.R.C.; data curation, A.B.; writing-original draft preparation, L.P., and A.B.; writing-review and editing, L.P., M.S., M.R.C. and A.B.; funding acquisition, M.S. and M.R.C. All authors have read and agreed to the published version of the manuscript.

Funding: This research received no external funding.

Conflicts of Interest: The authors declare no conflict of interest.

\section{References}

1. Buchta, V.; Černý, J.; Opletalová, V. In vitro antifungal activity of propolis samples of Czech and Slovak origin. Cent. Eur. J. Biol. 2011, 6, 160-166. [CrossRef]

2. Bankova, V.; Popova, M.; Trusheva, B. Propolis volatile compounds: Chemical diversity and biological activity: A review. Chem. Cent. J. 2014, 8, 28. [CrossRef] [PubMed]

3. Benhanifia, M.; Shimomura, K.; Tsuchiya, I.; Inui, S.; Kumazawa, S.; Mohamed, W.M.; Boukraa, L.; Sakharkar, M.K.; Benbarek, H. Chemical composition and antimicrobial activity of propolis collected from some localities of Western Algeria. Acta Aliment Hung. 2014, 43, 482-488. [CrossRef]

4. Nedji, N.; Loucif-Ayad, W. Antimicrobial activity of Algerian propolis in foodborne pathogens and its quantitative chemical composition. Asian Pac. J. Trop. Dis. 2014, 4, 433-437. [CrossRef]

5. Ö̈zan, M.; Ünver, A.; Ceylan, D.A.; Yetiflir, R. Inhibitory effect of pollen and propolis extracts. Nahrung 2004, 48, 188-194. [CrossRef] [PubMed]

6. Seibert, J.B.; Bautista-Silva, J.P.; Amparo, T.R.; Petit, A.; Pervier, P.; Dos Santos Almeida, J.C.; Azevedo, M.C.; Silveira, B.M.; Brandão, G.C.; de Souza, G.H.B.; et al. Development of propolis nanoemulsion with antioxidant and antimicrobial activity for use as a potential natural preservative. Food Chem. 2019, 287, 61-67. [CrossRef]

7. Silva, F.R.G.; Matias, T.M.S.; Souza, L.I.O.; Matos-Rocha, T.J.; Fonseca, S.A.; Mousinho, K.C.; Santos, A.F. Phytochemical screening and in vitro antibacterial, antifungal, antioxidant and anitumor activities of the red própolis Alagoas. Braz. J. Biol. 2019, 79, 452-459. [CrossRef]

8. Soylu, E.M.; Özdemir, A.E.; Ertürk, E.; Sahinler, N. Antifungal activity of propolis against postharvest disease agent Penicillium digitatum. Asian J. Chem. 2008, 24, 4823-4830.

9. Anjum, S.I.; Ullah, A.; Ali Kan, K.; Attaullah, M.; Khan, H.; Ali, H.; Bashir, M.A.; Tahir, M.; Ansari, M.J.; Ghramh, H.A.; et al. Composition and functional properties of propolis (bee glue): A review. Saudi J. Biol Sci. 2019, 26, 1695-1703. [CrossRef]

10. Kubilene, L.; Laugaliene, V.; Pavilonis, A.; Maruska, A.; Majiene, D.; Barcauskaite, K.; Kuilius, R.; Kasparavicine, G.; Savickas, A. Alternative preparation of propolis extracts: Comparison of their composition and biological activities. BMC Compl. Alt. Med. 2015, 15, 156. [CrossRef] 
11. Bodini, R.B.; Sobral, P.J.A.; Favaro-Trindade, C.S.; Carvalho, R.A. Properties of gelatin-based films with added ethanol-propolis extract. LWT-Food Sci. Technol. 2011, 51, 104-110. [CrossRef]

12. Dias, L.G.; Pereira, A.N.; Estevinho, L.M. Comparative study of different Portuguese samples of propolis: Pollinic, sensorial, physicochemical, microbiological characterization and antibacterial activity. Food Chem. Toxicol. 2012, 50, 4246-4253. [CrossRef] [PubMed]

13. Grange, J.M.; Davey, R.W. Antibacterial properties of propolis (bee glue). J. Roy. Soc. Med. 1990, 83, $159-160$. [CrossRef] [PubMed]

14. Kim, M.J.; Kim, C.S.; Kim, B.H.; Ro, S.B.; Lim, Y.K.; Park, S.N.; Cho, E.; Ko, J.H.; Kwon, S.S.; Ko, Y.M.; et al. Antimicrobial effect of Korean propolis against the mutans streptococci isolated from Korean. J. Microbiol. 2011, 49, 161-164. [CrossRef]

15. Mascheroni, E.; Figoli, A.; Musatti, A.; Limbo, S.; Drioli, E.; Suevo, R.; Talarico, S.; Rollini, M. An alternative encapsulation approach for production of active chitosan-propolis beads. Int. J. Food Sci. Technol. 2014, 49, 1401-1407. [CrossRef]

16. Righi, A.A.; Alves, T.R.; Negri, G.; Marques, L.M.; Breyer, H.; Salatino, A. Brazilian red propolis: Unreported substances, antioxidant and antimicrobial activities. J. Sci. Food Agric. 2011, 91, 2363-2370. [CrossRef]

17. Siripatrawan, U.; Vitchayakitti, W.; Sanguandeekul, R. Antioxidant and antimicrobial properties of Thai propolis extracted using ethanol aqueous solution. Int. J. Food Sci. Technol. 2013, 48, 22-27. [CrossRef]

18. Bevilacqua, A.; Corbo, M.R.; Sinigaglia, M. Inhibition of Alicyclobacillus acidoterrestris spores by natural compounds. Int. J. Food Sci Technol. 2008, 43, 1271-1275. [CrossRef]

19. Bevilacqua, A.; Ficelo, S.; Corbo, M.R.; Sinigaglia, M. Bioactivity of grapefruit extract against Pseudomonas spp. J. Food Process. Preserv. 2010, 34, 495-507. [CrossRef]

20. Bevilacqua, A.; Perricone, M.; Cannarsi, M.; Corbo, M.R.; Sinigaglia, M. Technological and spoiling characteristics of the yeast microflora isolated from Bella di Cerignola table olives. Int. J. Food Sci. Technol. 2009, 44, 2198-2207. [CrossRef]

21. Mafart, P.; Couvert, O.; Gaillard, S.; Leguerinel, I. On calculating sterility in thermal preservation methods: Application of the Weibull frequency distribution model. INT. J. Food Microbiol. 2002, 72, 107-113. [CrossRef]

22. Sinigaglia, M.; Corbo, M.R.; Ciccarone, C. Influence of temperature, $\mathrm{pH}$ and water activity on "in vitro" inhibition of Penicillium glabrum (Wehmer) Westling by yeasts. Microbiol. Res. 1998, 153, 137-143. [CrossRef]

23. Dantigny, P.; Nanguy, S.P.-M.; Judet-Correia, D.; Bensoussan, M. A new model for germination of fungi. Int. J. Food Microbiol. 2011, 146, 176-181. [CrossRef] [PubMed]

24. Mutlu Sariguzel, F.; Berk, E.; Koc, A.N.; Sav, H.; Demir, G. Antifungal activity of propolis against yeasts isolated from blood culture: In vitro evaluation. J. Clin. Lab. Anal. 2016, 30, 513-516. [CrossRef]

25. AL-Ani, I.; Zimmermann, S.; Reichling, J.; Wink, M. Antimicrobial activities of european propolis collected from various geographic origins alone and in combination with antibiotics. Medicines 2018, 5, 2. [CrossRef] [PubMed]

26. Andreani, A.A.; Fasolato, L. Pseudomonas and related genera. In The Microbiological Quality of Food. Foodborne Spoilers; Bevilacqua, A., Corbo, M.R., Sinigaglia, M., Eds.; Woodhead Publishing: Duxford, UK, 2017; pp. 25-59.

27. Perricone, M.; Gallo, M.; Corbo, M.R.; Sinigaglia, M.; Bevilacqua, A. Yeasts. In The Microbiological Quality of food. Foodborne Spoilers; Bevilacqua, A., Corbo, M.R., Sinigaglia, M., Eds.; Woodhead Publishing: Duxford, UK, 2017; pp. 121-132.

28. Nwakanma, C.; Unachukwu, M. Molds. In The Microbiological Quality of Food. Foodborne Spoilers; Bevilacqua, A., Corbo, M.R., Sinigaglia, M., Eds.; Woodhead Publishing: Duxford, UK, 2017; pp. 133-150.

29. Bevilacqua, A.; Campaniello, D.; Sinigaglia, M.; Ciccarone, C.; Corbo, M.R. Sodium benzoate and citrus extract increase the effect of homogenization towards spores of Fusarium oxysporum in pineapple juice. Food Control 2012, 28, 199-204. [CrossRef]

30. De Castro, P.A.; Savoldi, M.; Bonatto, D.; Barros, M.H.; Goldman, M.H.; Berretta, A.A.; Goldman, G.H. Molecular characterization of propolis-induced cell death in Saccharomyces cerevisiae. Eukaryot. Cell 2011, 10, 398-411. [CrossRef]

31. Sidra, Z.T. Propolis effect of the Iraqi (Iraqi propolis) in some types of yeasts that cause damage to fruit juices. DJPS 2010, 6, 227-239. 
32. Bartkiene, E.; Lele, V.; Sakiene, V.; Zavistanaviciute, P.; Zokaityte, E.; Dauksiene, A.; Jagminas, P.; Klupsaite, D.; Bliznikas, S.; Ruzauskas, M. Variations of the antimicrobial, antioxidant, sensory attributes and biogenic amines content in Lithuania-derived bee products. LWT-Food Sci. Technol. 2020, 118, 108793. [CrossRef]

33. Daikh, A.; Segueni, N.; Dogan, N.M.; Arslan, S.; Mutlu, D.; Kivrak, I.; Akkal, S.; Rhouati, S. Comparative study of antibiofilm, cytotoxic activity and chemical composition of Algerian propolis. J. Apicult. Res. 2020, 59, 2. [CrossRef]

34. de Mélo Silva, I.S.; do Amorim Costa Gaspar, L.M.; Rocha, A.M.O.; da Costa, L.P.; Tada, D.B.; Franceschi, E.; Padilha, F.F. Encapsulation of red propolis in polymer nanoparticles for the destruction of pathogenic biofilms. AAPS PharmSciTech 2010, 21, 49. [CrossRef] [PubMed]

35. Letullier, C.; Manduchet, A.; Dlalah, N.; Hugou, M.; Georgé, S.; Sforcin, J.M.; Cardinault, N. Comparison of the antibacterial efficiency of propolis samples from different botanical and geographic origins with and without standardization. J. Apicult. Res. 2020, 59, 1. [CrossRef]

36. Seidel, V.; Peyfoon, E.; Watson, D.G.; Fearnley, J. Comparative study of the antibacterial activity of propolis from different geographical and climatic zones. Phytother. Res. 2008, 22, 1256-1263. [CrossRef] [PubMed]

37. Perricone, M.; Arace, E.; Corbo, M.R.; Sinigaglia, M.; Bevilacqua, A. Bioactivity of essential oils: A review on their interaction with food components. Front. Microbiol. 2015, 6, 76. [CrossRef]

38. Speranza, B.; Corbo, M.R. Essential oils for preserving perishable foods: Possibilities and limitations. In Application of Alternative Food Preservation Technologies to Enhance Food Safety and Stability; Bevilacqua, A., Corbo, M.R., Sinigaglia, M., Eds.; Bentham Science: Sharjah, United Arab Emirates, 2010; pp. 35-57.

39. Meto, A.; Colombari, B.; Meto, A.; Boaretto, G.; Pinetti, D.; Marchetti, L.; Benvenuti, S.; Pellati, F.; Blasi, E. Propolis affects Pseudomonas aeruginosa growth, biofilm formation, eDNA release and phenazine production: Potential involvement of polyphenols. Microorganisms 2020, 8, 243. [CrossRef]

40. Speranza, B.; Racioppo, A.; Sinigaglia, M.; Corbo, M.R.; Bevilacqua, A. Use of Central Composite Design in food microbiology: A case study on the effects of secondary phenolis on lactic acid bacteria from olives. Int. J. Food Sci. Nutr. 2015, 66, 520-525. [CrossRef]

41. Ôzcan, M. Antifungal properties of propolis. Grasas Aceites 1999, 50, 395-398. [CrossRef]

42. Ahmed, S.D.; Mohanad, A.K.; Zaid, N.H. Study antifungal activity of ethanol extract propolis against Fusarium oxysporum fungi. J. Res. Diyala Humanit. 2008, 31, 93-105.

43. Shehu, A.; Ismail, S.; Rohin, M.A.K.; Harun, A.; Aziz, A.A.; Haque, M. Antifungal Properties of Malaysian tualang honey and stingless bee propolis against Candida albicans and Cryptococcus neoformans. J. Appl. Pharm. 2016, 6, 44-50. [CrossRef]

44. Lambert, R.J.W.; Pearson, J. Susceptibility testing: Accurate and reproducible minimum inhibitory concentration (MIC) and non-inhibitory concentration (NIC) values. J. Appl. Microbiol. 2000, 88, 784-790. [CrossRef]

45. Maskeroni, E.; Guillard, V.; Nalin, F.; Mora, L.; Piergiovanni, L. Diffusivity of propolis compounds in polylactic acid polymer for the development of anti-microbial packaging films. J. Food Eng. 2010, 98, $294-301$. [CrossRef]

46. Rizzolo, A.; Bianchi, G.; Povolo, M.; Migliori, C.A.; Contarini, G.; Pelizzola, V.; Cattaneo, T.M.P. Volatile compound composition and antioxidant activity of cooked ham slices packed in propolis-based active packaging. Food Packag. Shelf Life 2016, 8, 41-49. [CrossRef]

(C) 2020 by the authors. Licensee MDPI, Basel, Switzerland. This article is an open access article distributed under the terms and conditions of the Creative Commons Attribution (CC BY) license (http://creativecommons.org/licenses/by/4.0/). 